\title{
Chitosan-Coated Collagen-Hyaluronic Acid-Poly Ethylene Oxide- Based Electrospun Membrane for Corneal Ulcers Wound Dressing Candidate
}

\author{
Alfian Pramudita PUTRA ${ }^{1, *}$, Eva FAHMADIYAH ${ }^{1}$, \\ Dyah HIKMAWATI ${ }^{2}$ and Aminatun ${ }^{2}$ \\ ${ }^{1}$ Biomedical Engineering Study Program, Department of Physics, Faculty of Science and Technology, \\ Universitas Airlangga, Surabaya, Indonesia \\ ${ }^{2}$ Physics Study Program, Department of Physics, Faculty of Science and Technology, \\ Universitas Airlangga, Surabaya, Indonesia
}

('Corresponding author's e-mail: alfian.pramudita@fst.unair.ac.id)

Received: 10 January 2019, Revised: 31 March 2019, Accepted: 5 April 2019

\begin{abstract}
Corneal disease is the $2^{\text {nd }}$ biggest reason of blindness after cataract. Based on WHO data, it was predicted that 10 million people in the world would suffer from cornea-related sight deficiency. One of the solutions is by using wound dressing to cover the cornea so that it could heal effectively. Several studies were conducted to observe the use of collagen, hyaluronic acid, and PEO for wound dressing. To increase the properties of the membrane, chitosan coating was introduced. In this study, we observe the effect of chitosan coating on the electrospun membrane based on collagen, hyaluronic acid, and PEO combined with glutaraldehyde as a crosslinker. The result in FTIR test showed that the crosslinking process ended up in new bond formed among the materials used in this study. The chitosan coating could increase the transparency of the membrane as shown by the result of UV/Vis Spectrophotometry test but the result was not significantly different ( $p$-value $>0.05)$. The morphology test using SEM showed that the pore diameter of the membrane decreased with the presence of chitosan coating ( $p$-value $<0.05)$. Likewise, with an increase of chitosan coating concentration, the pores diameter also decreased. The cytotoxicity test showed that the membrane with several chitosan coating concentrations were non-toxic with cell viability more than $50 \%(p$-value $<0.05)$. The chitosan coating also had antibacterial effect as shown by the inhibition zone ( $p$-value $<0.05$ ), especially to Pseudomonas aeruginosa as gram positive bacteria. In conclusion, the presence of chitosan coating could improve the characteristics of the electrospun membrane coated with chitosan for wound dressing in corneal ulcers case.
\end{abstract}

Keywords: Chitosan coating, Collagen, Hyaluronic acid, Electrospinning, Cornea ulcers, Wound dressing

\section{Introduction}

Ulcers in cornea which are mostly caused by disease or wound could lead to blindness. Corneal disease is the $2^{\text {nd }}$ biggest reason of sight deficiency or blindness after cataract [1]. The genetic or defect corneal disease causes the loss of corneal transparency and visual dysfunction. Such a disease is caused by corneal ulcers shown by the presence of scar tissue which can lead to sight deficiency and blindness around the world [2].

Corneal ulcers are pathological condition in which the part of the corneal surface is missing or discontinued due to the death of corneal tissue. This condition is caused by bacteria, fungi or virus in the 
http://wjst.wu.ac.th

cornea which can lead to infection or inflammation [3]. Based on WHO data, it is predicted that 10 million people in the world would suffer from cornea-related sight deficiency or disease $[4,5]$.

The $1^{\text {st }}$ treatment for corneal ulcers is by giving antibiotics, antimicrobial or antifungal agents. However, the intake of these drugs is not always obeyed by the patients which can worsen the condition. When a treatment is not successful and becomes a scar tissue, the last solution is keratoplasty [6]. Besides that, several procedures can be undertaken to support the tissue repair and inflammation control by designing biomaterials that could reconstruct the damaged cornea. One of the solutions is by transplanting amniotic membrane. But, like the other allograft, amniotic membrane is limited only to the number of the donor and it has always the risk of contaminating this contagious disease. Thus, there is a need to investigate a novel biomaterial that has biocompatible properties and could stimulate the re-epitelization of the corneal tissue.

Several biomaterials were investigated to be applied in the cornea by using polymers, such as chitosan, caprolactone fibrin, collagen hydrogel, etc. The natural macromolecules like collagen, chitosan, hyaluronic acid and synthetic polymer like polyethylene oxide (PEO) could be used to produce fibrous membrane [7]. Collagen is a natural polymer that is biocompatible and vastly applied in the human body as implants in the bone, cartilage, tendon, skin, heart valve and cornea. The type I collagen is the main component of stroma and extracellular matrix (ECM) so that it is commonly used in the corneal tissue engineering [8]. To support collagen in wound healing process, a hyaluronic acid could be used due to its role in tissue repair. This material could also control the tissue hydration and water transport and maintain the viscoelasticity of liquid connective tissue, such as synovial fluid in the joints or vitreous humor in the cornea [9].

The use of collagen as a membrane was developed into a nanofiber membrane by using electrospinning method. The most usual problem in this method is the presence of beads in the fibers which weakens the membrane mechanical properties. These beads also affect the surface morphology of the membrane. Ye et al. [7] synthesized the nanofiber membrane from polyethylene oxide combined with collagen and hyaluronic acid and modified by chitosan. They reported that the membrane was transparent and had a high performance in mechanical properties. Chitosan is a polysaccharide that has high biological characteristics, especially in antibacterial properties. It is also non-toxic, biocompatible and biodegradable [10]. This material has been used as coating material due to its superior antimicrobial properties, optical property improvement, and adhesion enhancement [7,11]. For wound management, chitosan could provide histological organization, mechanical properties enhancement of the wound, and wound healing acceleration including proliferation of fibroblast cell [12]. To improve the morphology and transparency of the membrane, this study aims to investigate and optimize the variation of concentration of chitosan coating.

\section{Materials and methods}

\section{Materials}

The materials used in this study were polyethylene oxide (Sigma Aldrich, Singapore Mw: 600.000 $\mathrm{gr} / \mathrm{mol}$ ), Type I collagen (Biochitosan, Indonesia), hyaluronic acid, chitosan (Biochitosan, Indonesia), glutaraldehyde (Sigma Aldrich, Singapore), methanol, PBS, aluminum foil and deionized water.

\section{Collagen-hyaluronic acid-PEO solutions}

The Collagen (COL), hyaluronic acid (HA) and poly ethylene oxide (PEO) were prepared in a ratio of 80: 5: 15. All of them were mixed and dissolved in $10 \mathrm{~mL} 80 \mathrm{v} / \mathrm{v} \%$ methanol to obtain $10 \mathrm{wt} \%$ of mixed solution. It was mixed with a magnetic stirrer for $3 \mathrm{~h}$ at speed of $300 \mathrm{rpm}$ and at room temperature.

\section{Electrospinning process}

The Electrospinning process was performed by electrospinning device (GenLab HK 7, Indonesia) with a high voltage difference of $8.5 \mathrm{kV}$, solution flow rate of $20 \mu \mathrm{L} / \mathrm{h}$, and distance between collector and needle of $17 \mathrm{~cm}$ at room temperature and $50 \%$ of relative humidity. This process was carried out for $5 \mathrm{~h}$. The collector was a flat collector covered with an aluminum foil. 
http://wjst.wu.ac.th

\section{Glutaraldehyde crosslinking and chitosan coating process}

The fibrous membrane was then crosslinked by using $25 \mathrm{v} / \mathrm{v} \%$ glutaraldehyde for $24 \mathrm{~h}$ at room temperature with vapor method to increase the membrane stability in liquid medium. This process was performed by putting the fibrous membrane on the metal mesh above the glutaraldehyde solution on a closed beaker glass. The color of the membrane changed to yellowish brown and shrunk in term of size. The duration of crosslinking process affected the optical transparency of the membrane. Several studies reported that glutaraldehyde was toxic at a certain concentration and it is also a carcinogenic agent. Glutaraldehyde was chosen due to its primary function as a cross linker which increases the mechanical properties of materials. In this study, the crosslinking method was vapor method. This method was used due to the electrospun membrane which was easily dissolved in the solvents. The membrane was not in direct contact with glutaraldehyde. It also has been used several medical products, such as heart valve replacements and tissue products [13]. The crosslinking process was controlled by the height of vapor method and crosslinking time to maintain the uniformity of the crosslinking product. After the crosslinking process, the coating process was undertaken by preparing the chitosan solution in several concentrations $(0.5,1.0,1.5$, and $2.0 \mathrm{w} / \mathrm{v} \%)$. The chitosan was dissolved in $1 \mathrm{v} / \mathrm{v} \%$ acetic acid by using a magnetic stirrer for $4 \mathrm{~h}$ and let it rest for a night to let the bubble going out. Before the coating process, the membrane was rinsed with deionized water. The coating process was done for $3 \mathrm{~h}$ with immersion method at room temperature. The drying of coating process was performed at room temperature for $2 \mathrm{~h}$. The thickness of the coated membrane was $0.35 \pm 0.01 \mathrm{~mm}$.

\section{Functional group test using Fourier Transform Infrared (FTIR)}

The samples were characterized by Fourier Transform Infrared (FTIR) (IR Perkin Elmer) in Faculty of Science and Technology, Universitas Airlangga, Surabaya, Indonesia. The sample was added by $\mathrm{KBr}$ and formed into a pellet. This test was undertaken in the wavenumber of $4,000-400 \mathrm{~cm}^{-1}$.

\section{Transparency test}

The transparency (Visible light transmittance) of the sample was observed by using UV/Vis spectrophotometry (Hitachi UH 5300). The wet sample was cut into $5 \times 1 \mathrm{~cm}^{2}$ and placed inside the sample cuvette while the standard cuvette was filled with solvent of the sample. The result was the percentage of transmittance which indicates the transparency of the sample.

\section{Morphology test using Scanning Electron Microscope (SEM)}

The sample was characterized by Scanning Electron Microscope (SEM) (Phenom Pro X Dextop) with magnification of 1,5000 performed at Faculty of Science and Natural Science, State University of Semarang, Indonesia. The sample was $1^{\text {st }}$ coated with gold to increase the conductivity. The pore size and its spread was observed based on the SEM images.

\section{MTT assay test}

MTT assay method was used to observe the cytotoxicity properties of materials. The test was conducted at PUSVETMA, Surabaya by using Baby Hamster Kidney (BHK)-21 fibroblast cells. The cell that is alive would react by transforming the tetrazolium salt into formazan. The BHK-21 fibroblast cell in Eagle's media was incubated for $48 \mathrm{~h}$ and rinsed with Phosphate Buffer Saline (PBS). $100 \mu 1$ of $86 \%$ Eagle's media, $1 \%$ Penicillin streptomycin and 100 units of Fungizone/mL was prepared and the cultured cell was inserted into it. The cell culture was placed into 96-microwell plate. The sample with dimension of $0.5 \times 0.5 \mathrm{~cm}^{2}$ was put in each well and incubated for $24 \mathrm{~h}$ at $37^{\circ} \mathrm{C}$. The 96 -microwell plate was rinsed with PBS and was added $10 \mu \mathrm{l}$ of $5 \mathrm{mg} / \mathrm{mL}$ MTT solution in each well. It was added by $50 \mu 1$ of DMSO and then centrifuged for $5 \mathrm{~min}$ with $30 \mathrm{rpm}$. The measurement process was done by Elisa reader (Thermo Multiscan EX) indicating the violet level as Optical Density (OD) representing the cell viability of the material based on Eq. (1). The test was replicated 5 times $[13,14]$.

$\%$ cell viability $=(\mathrm{OD}$ treatment $+\mathrm{OD}$ media control $) /(\mathrm{OD}$ cell control + OD media control $)$ 
http://wjst.wu.ac.th

\section{Antibacterial test}

This test was performed to observe the sample resistance that has been coated with chitosan towards pathogen bacteria. The method used in this study was disc diffusion method by using Pseudomonas aeruginosa (as gram negative bacteria) and Staphylococcus aureus (as gram positive bacteria). The culture media was Mueller-Hinton Agar (MHA). This media was made by diluting 3.8 gr MHA in 1,000 $\mathrm{mL}$ distilled water and inserted on autoclave at temperature of $121^{\circ} \mathrm{C}$ for $15 \mathrm{~min}$. The solution was then let aside until the temperature was $40-50{ }^{\circ} \mathrm{C}$ and poured to a sterile petri dish. The compact agar was incubated at $37{ }^{\circ} \mathrm{C}$ for $24 \mathrm{~h}$. The bacteria colonies were taken by using OSE wire and put in the $5 \mathrm{~mL} 0.9$ $\%$ saline solution. The solution was incubated for $24 \mathrm{~h}$ and the turbidity was compared with the 0.5 McFarland standard turbidity. The bacteria was swapped zigzag on top of the agar media on the petri dish. The sample with dimension of $6 \times 6 \mathrm{~mm}^{2}$ was put on the bacteria culture and incubated for $24 \mathrm{~h}$. The evaluation of this method was performed by measuring the clear zone around the membrane which indicates the antimicrobial activity of the sample [16].

\section{Results and discussion}

\section{Synthesis of collagen-hyaluronic acid-PEO-based electrospun membrane}

The COL-HA-PEO-based electrospun membrane has been synthesized successfully. The result of electrospinning process was a white fibrous membrane on the surface of the aluminum foil. This membrane was dried in a room temperature. The crosslinking with glutaraldehyde and the coating process with several chitosan concentration on the membrane was performed which resulted to yellowish membrane. This membrane was then characterized in its functional group, morphology, optical transparency, cytotoxicity and antibacterial activity.

\section{Functional group test}

Figure 1 showed the FTIR result of collagen-HA-PEO-based electrospun membrane before and after crosslinked with glutaraldehyde and coated with chitosan. It showed that the specific functional group of every compound was in there, such as amide I stretching, $\mathrm{C}=\mathrm{O}, \mathrm{C}-\mathrm{O}-\mathrm{C}$ complex from chitosan, hyaluronic acid, and collagen at wavenumber of $1643.53,1406.64$, and $1082.67 \mathrm{~cm}^{-1}$, respectively. The absorption peak at wavenumber of $3434.41 \mathrm{~cm}^{-1}$ was the hydroxyl functional group from every material and also the result of crosslinking $[14,17,18]$. There was a slight shift of absorption peak of amide I functional group which indicated the result of crosslinking process. The shift was from 1651.40 to $1642.74 \mathrm{~cm}^{-1}$ because the formation of $\mathrm{C}=\mathrm{N}$ bond between amide I functional group from collagen and aldehyde functional group from glutaraldehyde [19].

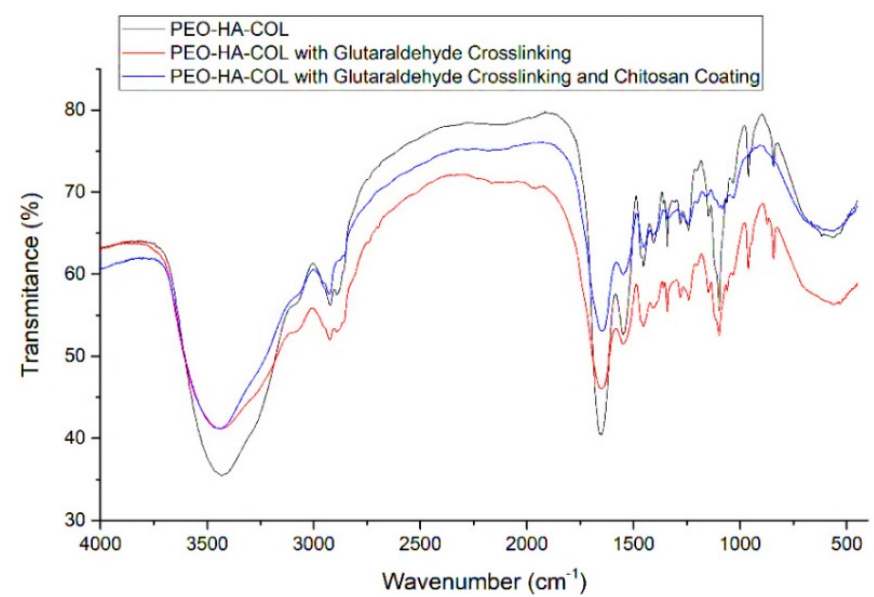

Figure 1 The FTIR spectra of the COL-HA-PEO-based electrospun membrane before the crosslinking, after the crosslinking and $0.5 \%$ chitosan coating. 
http://wjst.wu.ac.th

\section{Transparency test}

The UV/Vis spectroscopy test was used to observe the transparency of the synthesized membrane. This result was shown in Figures 2 and 3. The result illustrated that the transparency level of the sample increased with the addition of chitosan coating compared to the control sample which was the sample without chitosan coating [7]. The result with several chitosan coating concentrations did not show a linear trend since it decreased from 0.5 to $1.5 \mathrm{w} / \mathrm{v} \%$ of chitosan and increased again at $2 \mathrm{w} / \mathrm{v} \%$ of chitosan. The result was not significantly different ( $p$-value $>0.05$ ). This may be caused by the thickness of the coating. Since the coating process was a dip coating method, then the speed and the viscosity of the chitosan solution affected the thickness of the coating. Without controlling these parameters, the thickness would be slightly different from one sample to another sample. Moreover, the addition of chitosan could increase the transparency level due to the bonding among the chitosan and the collagen, hyaluronic acid and PEO that increased the optical properties of the sample [20]. The increase in optical property might be caused by the decrease of pore size. The change in surface property would make the light as an electromagnetic wave went through the sample behave differently. With the increase in chitosan concentration in the sample, there were a lot of amide functional group in the surface as a specific functional group of chitosan. The difference in color or transparency may be caused by the change in internal structures developed during the drying of the membrane [21].

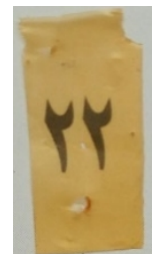

(a)

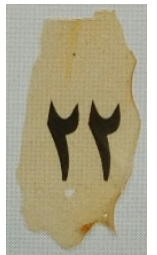

(b)

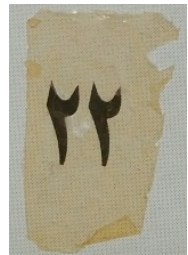

(c)

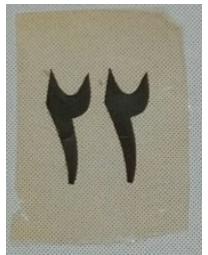

(d)

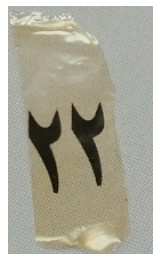

(e)

Figure 2 The transparency test of the COL-HA-PEO-based electrospun membrane after crosslinking process using glutaraldehyde with several chitosan coating concentration (a) $0 \mathrm{w} / \mathrm{v} \%$, (b) $0.5 \mathrm{w} / \mathrm{v} \%$, (c) 1 $\mathrm{w} / \mathrm{v} \%$, (d) $1.5 \mathrm{w} / \mathrm{v} \%$, (e) $2 \mathrm{w} / \mathrm{v} \%$.

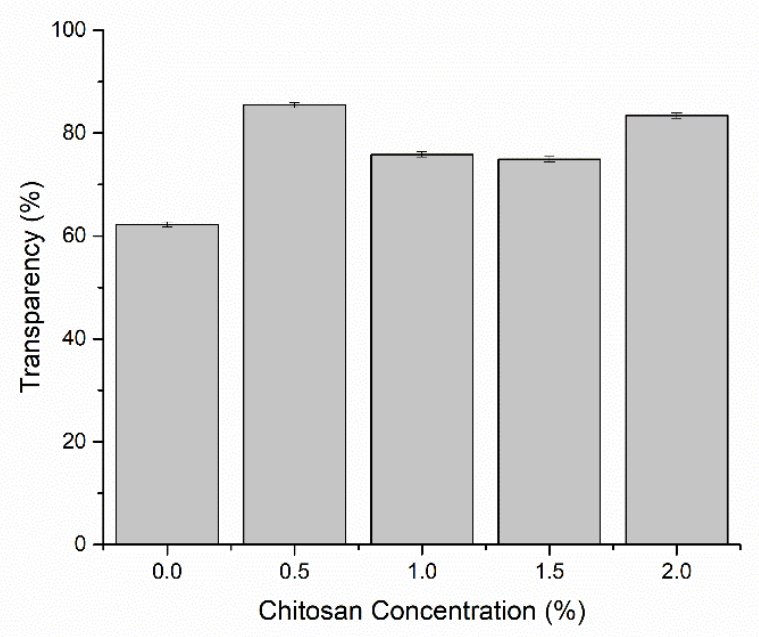

Figure 3 The UV/V is spectroscopy test of the COL-HA-PEO-based electrospun membrane after the crosslinking process using glutaraldehyde and chitosan coating. 
http://wjst.wu.ac.th

\section{Morphology test}

The morphology test was used to observe the surface structure of the tested sample. This test was performed on the sample without crosslinking and coating process and the sample with crosslinking and chitosan coating with several chitosan concentrations. The result was observed based on the pore diameter and distribution. Figure 4(a) depicted the electrospinning result from the materials used in this study which were collagen, hyaluronic acid and PEO with magnification of 8,000. The micro/nano fiber was successfully synthesized without the presence of beads. This result was obtained by using methanol as a solvent. After the crosslinking process by using glutaraldehyde, the morphology of the membrane changed [7]. The fibers were combined due to the crosslinking process and resulted to a membrane with pores shown in Figure 4(b). The fibers structure changed to porous structure with higher mechanical strength and stability. The pores were spread evenly. After the chitosan coating process, the result was shown Figures 4(c) - 4(f) with magnification of 15,000.

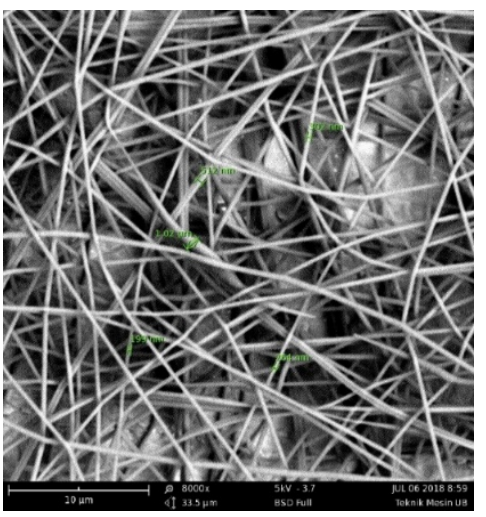

(a)

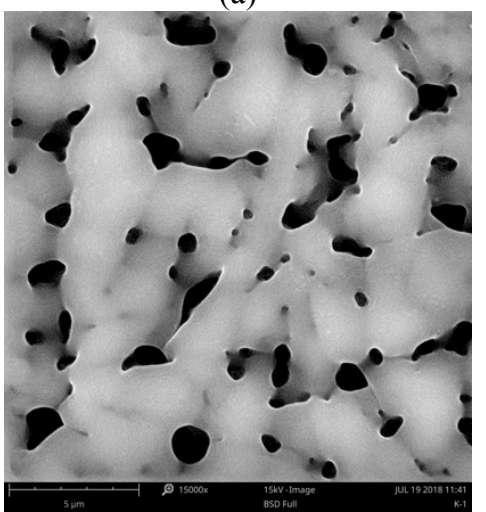

(d)

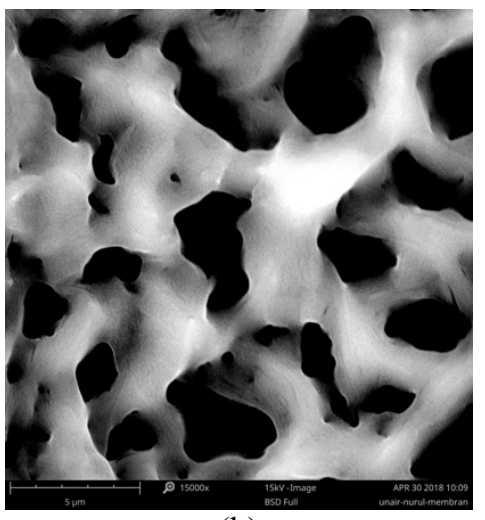

(b)

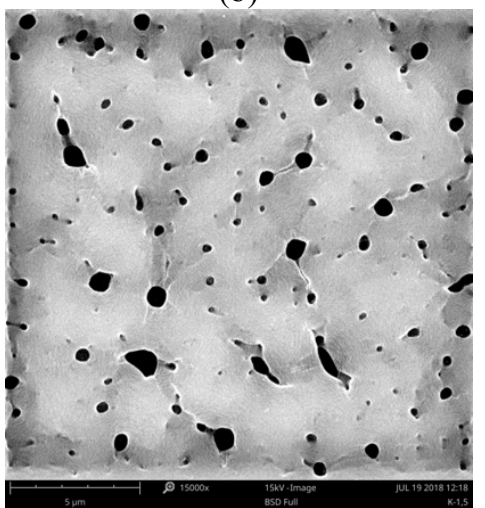

(e)

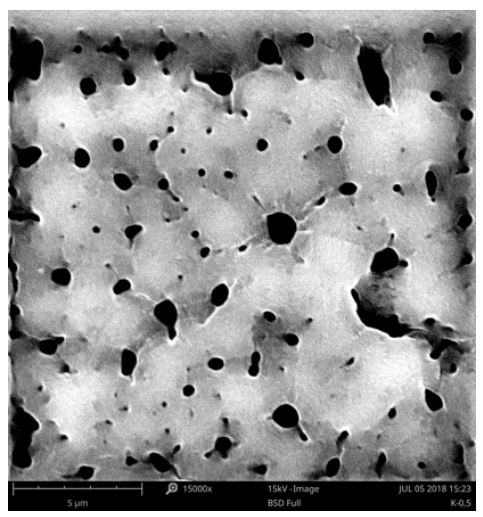

(c)

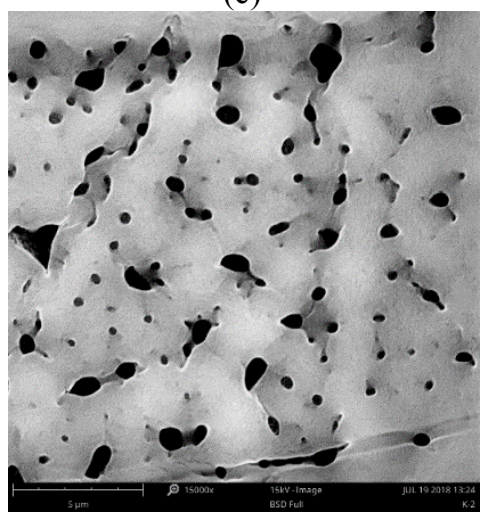

(f)

Figure 4 SEM images of the COL-HA-PEO-based electrospun membrane (a) without crosslinking and chitosan coating, (b) with crosslinking, but without chitosan coating, (c) with crosslinking and $0.5 \mathrm{w} / \mathrm{v} \%$ chitosan coating, (d) with crosslinking and $1 \mathrm{w} / \mathrm{v} \%$ chitosan coating, (e) with crosslinking and $1.5 \mathrm{w} / \mathrm{v} \%$ chitosan coating, (f) with crosslinking and $2 \mathrm{w} / \mathrm{v} \%$ chitosan coating

The effect of the chitosan coating was shown in Figure 5 which was the pore diameter average of the membrane without and with chitosan coating in several concentrations. The pore diameter before the chitosan coating which was $3.58 \mu \mathrm{m}$ was higher than the one after chitosan coating which was between 0.899 and $1.479 \mu \mathrm{m}$. This was caused by the chitosan solution which enveloped the pores and reduced the 
http://wjst.wu.ac.th

pore diameter. With the increase of chitosan coating concentration, the pore diameter of the membrane decreased too. The size of pores that is suitable for stratification of corneal epithelia cell was ranged from 0.1 to $0.8 \mu \mathrm{m}$. The corneal epithelia cell growth could be observed with pore size $0.4-0.8 \mu \mathrm{m}[20,22]$. The result of this study showed that the pore size of the membrane was slightly out of the range for the corneal epithelia cell to grow [23]. It is recommended to decrease the pore size by decreasing the chitosan concentration for the future study.

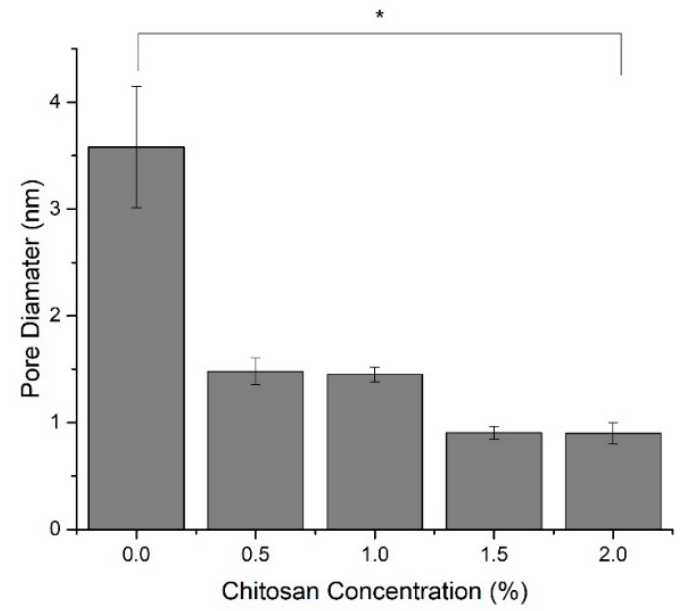

Figure 5 The pore diameter average of COL-HA-PEO-based electrospun membrane after the crosslinking process using glutaraldehyde and chitosan coating. The * marker shows a significant difference from ANOVA 1-way test with $p$-value $<0.05$.

\section{MTT assay test}

The MTT assay test was used to observe the toxicity property of the sample that is important for its application as corneal ulcers wound dressing. This test was using BHK-21 fibroblast cells and showed the cell viability due to the response towards the sample. MTT reactant has a function to detect the living cell when it interacts with the sample by showing a violet color. This color is originated from the formazan which is the result of MTT reactant with cell's mitochondria indicating that the cell is alive. This color was read by the Elisa reader indicating the cell viability by using a formula mentioned in Putra et al. (2018) [13]. The result was shown in Figure 6. All of the chitosan coating concentrations showed the cell viability above $50 \%$, which was non-toxic. The study of Telli et al. [15], Khoswanto et al. [24] and Ariani et al. [25] mentioned that when the cell viability of material above $50 \%$, the material is considered as non-toxic $[15,24,25]$. Another study also mentioned that the cell viability of materials should be more than $80 \%$ to be categorized as non-toxic. Based on this standard, the sample with chitosan coating concentration of 1 and $1.5 \mathrm{w} / \mathrm{v} \%$ was non-toxic. Moreover, there was no correlation between the increase of chitosan concentration and the cell viability. The cell viability of the sample with chitosan coating was lower than the one without coating. The presence of chitosan coating that used acetic acid as solvent could decrease the cell viability. Nonetheless, the membranes were still non-toxic with cell viability more than $50 \%$ or even more than $80 \%$. This property is important due to the aim of its application. For further study, the toxicity of the sample should be tested with the close cells to corneal epithelial cells to obtain more thorough information about its biological properties. 
http://wjst.wu.ac.th

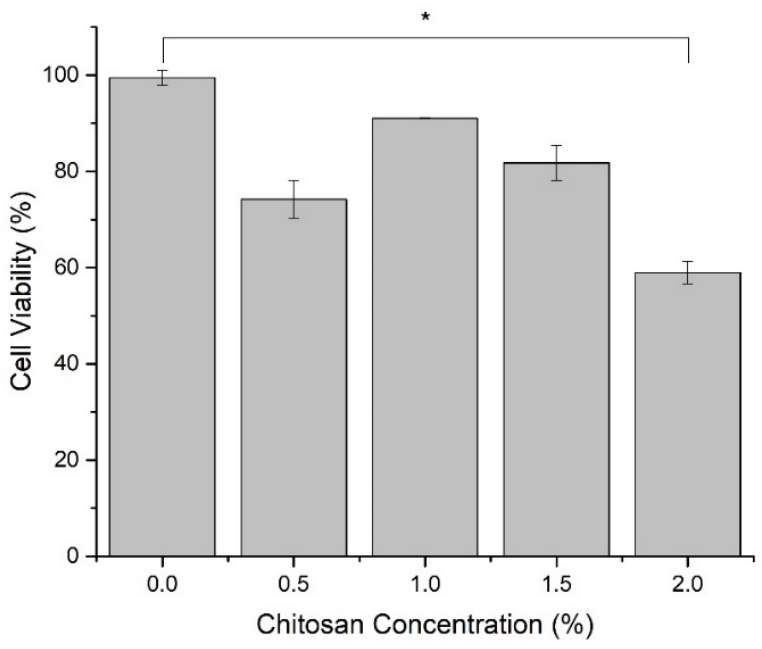

Figure 6 The cytotoxicity test on the COL-HA-PEO-based electrospun membrane after the crosslinking process using glutaraldehyde and chitosan coating. The * marker shows a significant difference between the several chitosan concentration from ANOVA 1-way test with $p$-value $<0.05$.

\section{Antibacterial test}

The antibacterial test by using disc diffusion method was performed with both gram negative and positive bacteria which were Pseudomonas aeruginosa and Staphylococcus aureus. Those 2 bacteria were one of bacteria caused corneal ulcers. The inhibition zones around the sample indicated the antibacterial activity of the sample. They showed that there was no inhibition zone and even the bacteria could grow on the surface of the membrane. The diameter of inhibition zone was measured and depicted in Figure 7.

Based on the study by Monks et al. [26], the antibacterial activity of the sample with chitosan concentration of 0.5 and $1 \mathrm{w} / \mathrm{v} \%$ was categorized as low antibacterial activity since it was $10 \mathrm{~mm}$ or less while the sample with chitosan concentration of 1.5 and $2 \mathrm{w} / \mathrm{v} \%$ was categorized as middle antibacterial activity for both bacteria. The result was significantly different since the $p$-value $<0.05$. The inhibition zone of the sample increased with the increase of chitosan concentration and they were significantly different with $p$-value of 0.000 . This result was suited with the study by Shanmugam et al. [27] that showed the increase of antibacterial activity on several gram positive and gram negative bacteria. In several cases, the antibacterial activity would reach its peak at low concentration (around $1.5-2 \mathrm{~g} / \mathrm{L}$ ) [28]. The low concentration of chitosan could have a better solute distribution with lower inter-chain interaction so that they could interact easier with the other molecules [29].

Chitosan has different antibacterial effects on gram positive (Staphylococcus aureus) and negative bacteria (Pseudomonas aeruginosa). Based on No et al. [30] and da Silva et al. [31], chitosan had better antibacterial effect on gram negative bacteria, such as Pseudomonas aeruginosa in this study. It emphasized the result of this study which showed that the sample had higher inhibition zone on Pseudomonas aeruginosa compared to that on Staphylococcus aureus. This was related to the wall properties and structure of the bacteria. The gram negative bacteria has thinner cell wall compared to the gram positive bacteria so that it was more vulnerable to the chitosan's antibacterial effect [30,31]. It was also supported with the wettability of the bacteria in which the gram negative bacteria was more hydrophilic than gram positive bacteria and lead to more sensitive to chitosan [32]. 
http://wjst.wu.ac.th

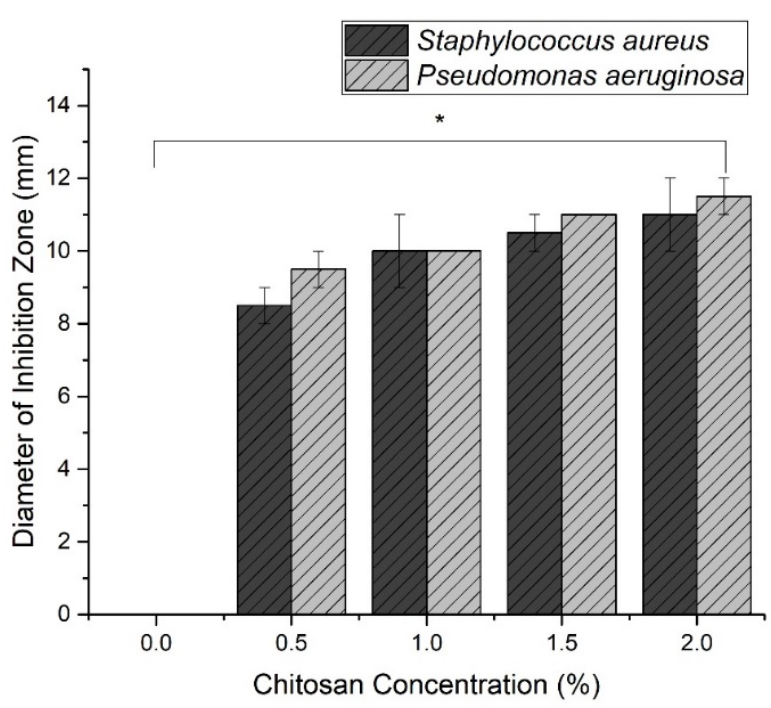

Figure 7 The diameter of inhibition zone of chitosan-coated COL-HA-PEO-based electrospun membrane on Staphylococcus aureus and Pseudomonas aeruginosa. The * marker shows a significant difference from ANOVA 1-way test with $p$-value $<0.05$.

\section{Conclusions}

The electrospun membrane based on collagen-hyaluronic acid and PEO was synthesized with several chitosan coating concentrations. The membrane was crosslinked by using glutaraldehyde with evaporation method. The functional group test using FTIR showed that the crosslinking process resulted in the new bond among the materials used in this study, especially the hydroxyl group and the aldehyde group from the glutaraldehyde. The transparency of the membrane did not increase significantly with the increase of chitosan coating concentration ( $p$-value $>0.05$ ). The morphology test using SEM indicated that the presence of chitosan coating reduce the pore diameter of the membrane from $3.58 \mu \mathrm{m}$ to between $0.889 \mathrm{~nm}$ and $1.479 \mu \mathrm{m}$. The increase in chitosan coating concentration also reduce the pore diameter of the membrane significantly $(p$-value $<0.05)$. The cytotoxicity test result showed that the membrane was non-toxic ( $p$-value $<0.05)$. The antibacterial test showed that the chitosan coating enhanced the antibacterial effect of the sample, especially to gram negative bacteria ( $p$-value $<0.05$ ). All of the characterization mentioned before indicated that the use of chitosan coating could improve the properties of the membrane for its application as wound dressing for corneal ulcers.

\section{Acknowledgements}

The authors would like to say thank you to Faculty of Science and Technology, Universitas Airlangga for giving funding to this research with No. 1888/UN3.1.8/LT/2018.

\section{References}

[1] X Zhang, XC Tao, J Zhang, ZW Li, YY Xu, YM Wang, ZX Zhang and GY Mu. A review of collagen cross-linking in cornea and sclera. J. Ophthalmol. 2015; 2015, 289467.

[2] R Amatya, S Shrestha, B Khanal, R Gurung, N Poudyal, SK Bhattacharya and BP Badu. Etiological agents of corneal ulcer: Five years prospective study in eastern Nepal. Nepal Med. Coll. J. 2012; 14, 219-22. 
http://wjst.wu.ac.th

[3] RS Katara, ND Patel and M Sinha. A clinical microbiological study of corneal ulcer patients at western Gujarat, India. Acta Med. Iran. 2013; 51, 399-403.

[4] C Deng, F Li, JM Hackett, SH Chaudhry, FN Toll, B Toye, W Hodge and M Griffith. Collagen and glycopolymer based hydrogel for potential corneal application. Acta Biomater. 2010; 6, 187-94.

[5] World Health Organization, Asia RO for SE. Guidelines for the Management of Corneal Ulcer at Primary, Secondary \& Tertiary Care Health Facilities in the South-East Asia Region. World Heal Organ Reg Off South-East Asia, New Delhi, 2004, p. 1-36.

[6] HR Yum, MS Kim and EC Kim. Retrocorneal membrane after Descemet membrane endothelial keratoplasty. Cornea 2013; 32, 1288-90.

[7] J Ye, X Shi, X Chen, J Xie, C Wang, K Yao, C Gao and C Gou. Chitosan-modified, collagen-based biomimetic nanofibrous membranes as selective cell adhering wound dressings in the treatment of chemically burned corneas. J. Mater. Chem B 2014; 2, 4226-36.

[8] CE Ghezzi, J Rnjak-Kovacina and DL Kaplan. Corneal tissue engineering: Recent advances and future perspectives. Tissue Eng. Part B Rev. 2015; 21, 278-87.

[9] KM Gronkiewicz, EA Giuliano, A Sharma and RR Mohan. Effects of topical hyaluronic acid on corneal wound healing in dogs: A pilot study. Vet. Opthalmol. 2017; 20, 123-30.

[10] X Wang, F Cheng, J Gao and L Wang. Antibacterial wound dressing from chitosan/polyethylene oxide nanofibers mats embedded with silver nanoparticles. J. Biomater. Appl. 2015; 29, 1086-95.

[11] W Li, Y Long, Y Liu, K Long, S Liu, Z Wang, Y Wang and L Ren. Fabrication and characterization of chitosan-collagen crosslinked membranes for corneal tissue engineering. J. Biomater. Sci. Polym. Ed. 2014; 25, 1962-72.

[12] AM Alsharabasy, SA Moghannem and WN El-Mazny. Physical preparation of alginate/chitosan polyelectrolyte complexes for biomedical applications. J. Biomater. Appl. 2016, 30, 1071-9.

[13] YY Peng, V Glattauer and JAM Ramshaw. Stabilisation of collagen sponges by glutaraldehyde vapour crosslinking. Int. J. Biomater. 2017; 2017, 8947823.

[14] AP Putra, AA Rahmah, N Fitriana, SA Rohim, M Jannah and D Hikmawati. The effect of glutaraldehyde on hydroxyapatite-gelatin composite with addition of alendronate for bone filler application. J. Biomimetics, Biomater. Biomed. Eng. 2018; 37, 107-16.

[15] C Khoswanto, E Arijani and P Soesilawati. Cytotoxicity test of 40, 50 and $60 \%$ citric acid as dentin conditioner by using MTT assay on culture cell line. Dent. J. 2008; 41, 103-106.

[16] EA Tendencia. Disk Diffusion Method. In: Laboratory Manual of Standardized Methods for Antimicrobial Sensitivity Tests for Bacteria Isolated from Aquatic Animals and Environment. Tignauan, Iloilo: Southeast Asian Fisheries Development Center, 2004, p. 13-29.

[17] S Wu, L Deng, H Hsia, K Xu, Y He, Q Huang, Y Peng, Z Zhou and C Peng. Evaluation of gelatinhyaluronic acid composite hydrogels for accelerating wound healing. J. Biomater. Appl. 2017; 31, 1380-90.

[18] RP Gonçalves, WH Ferreira, CT Andrade and U Federal. Effect of chitosan on the properties of electrospun fibers from mixed poly (vinyl alcohol)/chitosan solutions. Mater. Res. 2017; 20, 984-93.

[19] JP Chen, GY Chang and JK Chen. Electrospun collagen/chitosan nanofibrous membrane as wound dressing. Colloids Surf. A Physicochem. Eng. Asp. 2008; 313-314, 183-8.

[20] JH Fitton, BA Dalton, G Beumer, G Johnson, HJ Griesser and JG Steele. Surface topography can interfere with epithelial tissue migration. J Biomed. Mater. Res. 1998; 42, 245-57.

[21] J Mei, Y Yuan, Y Wu and Y Li. Characterization of edible starch-chitosan film and its application in the storage of Mongolian cheese. Int. J. Biol. Macromol. 2013; 57, 17-21.

[22] BA Dalton, MD Evans, GA McFarland and JG Steele. Modulation of corneal epithelial stratification by polymer surface topography. J. Biomed. Mater. Res. 1999; 45, 384-94.

[23] B Yanez-Soto, SJ Liliensiek, JZ Gasiorowski, CJ Murphy and PF Nealey. The influence of substrate topography on the migration of corneal epithelial wound borders. Biomaterials 2013; 34, 9244-51.

[24] C Telli, A Serper, AL Dogan and D Guc. Evaluation of the cytotoxicity of calcium phosphate root canal sealers by MTT assay. J. Endod. 1999; 25, 811-3.

[25] MD Ariani, A Yuliati and T Adiarto. Toxicity testing of chitosan from tiger prawn shell waste on cell culture. Dent. J. 2009; 42, 15-20. 
http://wjst.wu.ac.th

[26] NR Monks, C Lerner, AT Henriques, FM Farias, EES Schapoval, ES Suyenaga, AB Rocha, G Schwartsmann and B Mothes. Anticancer, antichemotactic and antimicrobial activities of marine sponges collected off the coast of Santa Catarina, southern Brazil. J. Exp. Mar. Bio. Ecol. 2002; 281, 1-12.

[27] A Shanmugam, K Kathiresan and L Nayak. Preparation, characterization and antibacterial activity of chitosan and phosphorylated chitosan from cuttlebone of Sepia kobiensis (Hoyle, 1885). Biotechnol. Rep. 2016; 9, 25-30.

[28] RC Goy and OBG Assis. Antimicrobial analysis of films processed from chitosan and N,N,Ntrimethylchitosan. Brazilian J. Chem. Eng. 2014; 31, 643-8.

[29] EF Palermo and K Kuroda. Structural determinants of antimicrobial activity in polymers which mimic host defense peptides. Appl. Microbiol. Biotechnol. 2010; 87, 1605-15.

[30] HK No, NY Park, SH Lee and SP Meyers. Antibacterial activity of chitosans and chitosan oligomers with different molecular weights. Int. J. Food Microbiol. 2002; 74, 65-72.

[31] LP da Silva, D de Britto, MHR Seleghim and OBG Assis. In vitro activity of water-soluble quaternary chitosan chloride salt against E. coli. World J. Microbiol. Biotechnol. 2010; 26, 2089-92.

[32] Y Chung, Y Su, C Chen, G Jia, H Wang, JCG Wu, J Lin. Relationship between antibacterial activity of chitosan and surface characteristics of cell wall. Acta Pharmacol. Sin. 2004; 25, 932-6. 